\title{
Micro Wind Turbines for Energy Gathering in Build Up Areas
}

\author{
Duong Minh Bui, Wim J.C. Melis \\ School of Engineering, University of Greenwich \\ Central Avenue, Chatham Maritime \\ United Kingdom
}

\begin{abstract}
In a city environment, wind direction is often not predictable and is easily re-directed in different ways by all kinds of obstacles. Consequently, large size wind turbines do not work effectively, not to mention the requirement for planning permission often needed for their installation. In an attempt to overcome these problems, this paper proposes the design of vertical-axis micro turbines with a maximum diameter of $30 \mathrm{~cm}$, which generate electric power for low voltage DC loads. The paper looks at the design, simulation and construction of a combination of Savonius-type, H-type and Darrieustype blade turbines. A variety of mechanical and electrical aspects of the turbine design are studied in detail to enhance the electrical output efficiency of the turbines. The results indicate that the most efficient turbine makes use of a combination of different blade designs, resulting in a power coefficient of $42 \%$ and an average total efficiency of about 32\%. Additionally, the turbine has a high electric power output, a good self-starting characteristic, and low starting and cut-in wind speeds of $2.25 \mathrm{~m} / \mathrm{s}$ and $2.75 \mathrm{~m} / \mathrm{s}$ respectively. It also benefits from a simple mechanical structure and can therefore be produced cheaply.
\end{abstract}

\section{Introduction}

Many countries around the globe have already invested significantly in large wind farms, either in the countryside, offshore, in the mountains or at the seaside. The energy gathered from these wind farms can fairly easily be predicted and calculated, since wind speed and direction are well known and there are few factors that will influence them [1]. However, in a built-up environment, wind speed and especially direction are far from predictable because they are influenced by all kind of obstacles such as skyscrapers, apartment blocks, etc. In spite of this problem, there are still several locations within the city where there is nearly always going to be a sufficient amount of wind to provide a continuous energy supply. A number of small-scale wind turbines are already commercially available, but on average they have a diameter of $50 \mathrm{~cm}$ and above, and require planning permission before being put up in a built-up environment.

The next section theoretically investigates the relationship between the size of a turbine, the amount of wind it requires and how much power will be generated as a consequence. Intuitively one can understand that lower wind-speeds require smaller and lighter turbines to generate energy. The benefit of these smaller turbines is that they possibly also overcome the required planning permission. Hence, this paper looks at several different designs of micro turbines with a diameter up to $30 \mathrm{~cm}$. This diameter size was chosen as a fair compromise between size and power generated. The design, simulation and prototypes of three different turbines are discussed in Section 3. This section also presents a detailed study of the mechanical structure and electrical components to optimise the actual turbine efficiency. The paper then moves onto the actual results for each of the turbines and compares them to determine the most efficient design, after which the paper concludes.

\section{Theoretical Study}

Before looking at the actual turbine design, it is important to understand the potential energy that could be gathered from wind. This calculation assumes that there is no change of air density or possible climate changes. A further assumption is that the generated power will be directly proportional to the contact surface area of the turbine blades as well as the wind velocity, which leads to the following equation to calculate the total mechanical power:

$$
P=C_{p}(\lambda) \frac{1}{2} \rho A V^{3}
$$

In the above equation $\mathrm{P}$, the mechanical power of the turbine, depends on $\rho$, the air density, $A$, the swept area, $V$, the average wind speed and $C_{P}(\lambda)$, the power coefficient of the turbine blades. The latter of which has a maximum value of $59.3 \%$ [2], and is generally referred to as the power coefficient. This also means that the maximum theoretical power of the turbine is limited by this power coefficient. Commonly, this power coefficient is much lower and lies within the range of 0.35 to 0.45 . Several parameters influence this power coefficient, 
including: average wind speed, rotational speed of the turbine, and pitch angle. Consequently, depending on the type of blades, the ratio of bladetip-speed to wind speed will be different as shown in Figure 1.

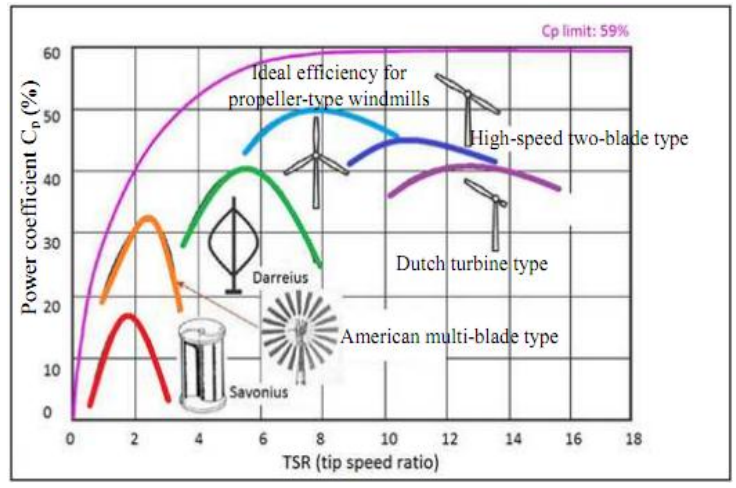

Figure 1. Power Coefficient vs. Tip Speed Ratio for different types of Turbines [2]

Considering the environment for which the turbine is being designed, one has to take into account the variety of directions from which the wind can come towards the turbine. Therefore, a vertical-axis turbine is more suitable, even though these turbines have a slightly lower efficiency [1]. Independent of the type of turbine, the positioning on or around the building also plays a significant role in the amount of power that is gathered [3]. Due to their small size it is easy to position these turbines at a variety of different locations, as long as they receive sufficient wind [4]. Such locations could be found around the roof of the house or even around the outside edges of the building. When looking at roof profiles, depending on the roof profile there are certain locations, which are better to position a turbine, as summarized in Table 1. Additionally, due to the characteristics of wind flow in relation to the roof type [5] a flat roof will result in higher output efficiencies than other roof profiles.

\section{Turbine design}

The turbines being designed in this project started from the known types, namely: Savonius-type, H-

Table 1. The proposed locations to build the vertical micro turbines, in relation to roof type

\begin{tabular}{|l|c|c|c|}
\hline \multirow{2}{*}{\multicolumn{1}{|c|}{ Roof Profiles }} & \multicolumn{3}{c|}{ Positions } \\
\cline { 2 - 4 } & Corner & Edge & Centre \\
\hline Pitched roof & $\checkmark$ & $\mathrm{x}$ & $\checkmark$ \\
\hline Flat roof & $\checkmark$ & $\checkmark$ & $\checkmark$ \\
\hline Pyramidal roof & $\checkmark$ & $\mathrm{x}$ & $\mathrm{x}$ \\
\hline
\end{tabular}

type and Darrieus-type turbines. These different types were then combined in order to bring together their respective advantages. The overall goal was to design a small Vertical Axis Wind Turbine (VAWT), which has high self-starting ability and total efficiency while remaining simple and cheap to manufacture.

To achieve this goal, a variety of different turbine designs were simulated to determine the effect of changes to the blade design. Figure 2 shows the simulation results for a 4-blade Savonius turbine with (b) or without (a) windshields. Combining the results of these simulations, a limited number of designs seemed beneficial towards being build as a physical prototype. Building an actual prototype does not only require the blade design to be considered, but there are additional design decisions to be made. For most of these design decisions, multiple options were taken to allow for a comparison of their impact on the overall prototype and power output.

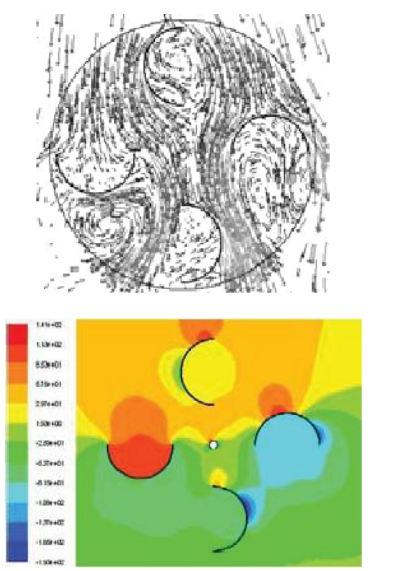

(a)
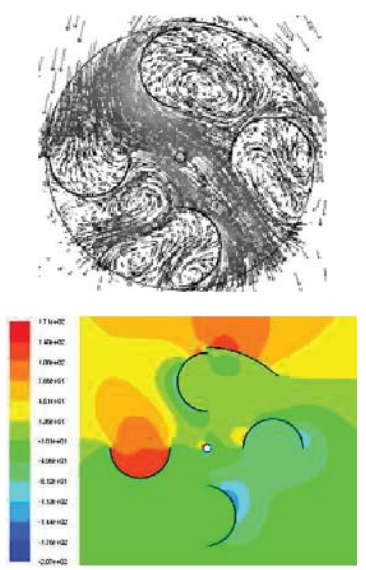

(b)
Figure 2: Simulation results for Savonious turbine without (a) and with (b) H-type Windshields.

\subsection{Mechanical components for the turbines}

3.1.1. Solid Mount Frame for Turbine The main purpose of building a solid frame is to ensure that the turbine blades remain stable when they rotate around their shaft. To achieve this, the frame must be able to resist static forces from the weight of turbine blades; and dynamic forces produced by vibrations of the rotating elements as well as the fluctuating thrust forces due to sudden changes in wind speed. The frame used within this research makes use of steel hollow tubes, which are mounted together using plastic quick-fix connectors. The frame has a length of $400 \mathrm{~mm}$, a width of $300 \mathrm{~mm}$ and a height of $150 \mathrm{~mm}$.

When designing a VWAT, one has the choice of fixing the central rod to the blades and rotating it within the base or fixing the rod and allowing the blades to rotate around it. There are advantages and 
disadvantages to either approach, but in this specific case the shaft was fixed to the frame and the blade structure would be mounted around it making use of ball bearings at the points of connection. A variety of different bearings were tested as will be described later.

3.1.2. Turbine Blade Design Taking that H-type turbine blades have an equal radius through the whole length of the blade, the swept area will be constant, resulting in a constant power for a constant wind speed. Additionally, H-type blades have a higher efficiency and rotation speed for the same wind speed, when compared to other turbine blades. This however comes with the disadvantage of a poor self-starting ability. On the other hand, Savoniustype blades have better self-starting characteristics than Darrieus or H-type blades. This is due to the larger amount of surface area against the wind direction [6], resulting in the blades dispersing the momenta forces on the axis with a larger angle. Consequently a combination of these two turbine types is considered to overcome the self-starting problem of the H-type turbine.

The first turbine is a four blade Savonius-type combined with four windshields, which are actually H-type blades. The windshields were added to optimise the airflow impacting the S-type turbine blades. A small gap between the windshields and four turbine blades is created to disperse the airflow easily and reduce the negative torque affecting the turbine shaft. The size of the designed prototype is $30 \mathrm{~cm} \times 40 \mathrm{~cm}$, with an internal radius of $30 \mathrm{~mm}$ for the S-type blades and $30 \mathrm{~cm}$ being the outside diameter of the setup. The angle between the windshields and $\mathrm{X}$-axis was determined to be optimal at $30^{\circ}$. A picture of this turbine can be seen in Figure 3 (a).

The second turbine is an H-type with three blades combined with three Savonius-type blades (see Figure 3 (b)). The use of the S-type blades enhances the dynamic torque performance of the VAWT at high rotation, while it will also reduce the dynamic torque performance at low tip speed ratio. Combining the H-type with an S-type allows for an overall better performance. It should be mentioned that the angle of attack of each Savonius-type blade on the prototype could be adjusted, but also that their configurations are different from that in turbine 1 . The chord length of the H-blade in this design is longer than for Turbine 1, but also the acute angle created by the chord of the H-blade and the X-axis at about $40-45^{\circ}$ is larger in comparison with the configuration of Turbine $1\left(30^{\circ}\right)$. The $45^{\circ}$ includes a pitch angle of $15^{\circ}$ and an optimal angle of attack of $30^{\circ}$. Additionally, the diameter of the three S-type blades is about $60 \mathrm{~mm}$ to enhance the self-starting time in conditions with frequent changes in wind speed. This turbine uses only 3 blades to avoid the blades to obstruct each other for different wind directions.

The third prototype turbine is a Darrieus-type turbine with three blades (See Figure 3 (c)). This lifttype turbine is appropriate for both low wind speed and frequent changes in wind direction. On top of that, it is also highly efficient [7] and is well known for its smooth operation, minimal vibrations and limited acoustic noise. This turbine is designed with a small pitch angle of about $30^{\circ}$. However, this value can again be changed in the designed prototype. It is well known that a Darrius turbine operates well with a diameter above $50 \mathrm{~cm}$ [8, 9], but their characteristics for a diameter below $50 \mathrm{~cm}$ are not that highly spoken from.
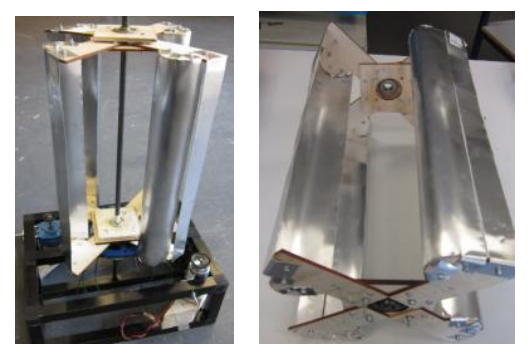

(a) A four-blade Savonius turbine with windshields
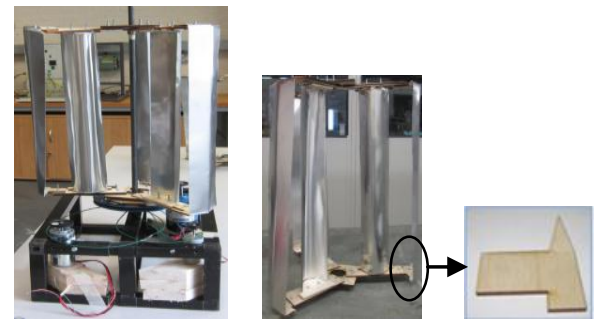

(b) A 3-blade Savonius turbine with H-type blades and the plywood used to form and mount the blades

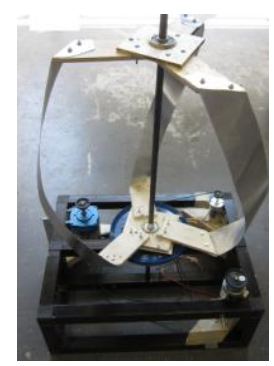

(c) A Darrieus-type turbine with 3 blades

Figure 3. Different Turbine Designs

3.1.3. Transferring the Turbine Rotations to the Generator As mentioned earlier, the turbine rotates around a central shaft. The connection between both would be making use of bearings. Using bearings for this connection has a set of advantages [10]. Various types of bearings were selected for testing, namely: ball bearings, taper roller bearings, and 2bolt circle bearings. The best type of bearings will have low friction resulting in a limited energy loss. Additionally factors, like the amount of vibrations 
and dynamic forces of the wind turbines will also affect the selection of the most appropriate bearings.

Considering that these turbines are used in an environment with varied wind speeds, which will on average be rather low, this would also mean that the rotational speed of the turbine would be low. Such low rpms result in an inefficient conversion to electrical energy in the actual generator. The latter of which is generally more efficient when it rotates at higher rpm, therefore quite often wind turbines have a gear system to increase the speed of the rotor from the turbine before reaching the generator. Gearboxes have the benefit of a higher lifetime, but they are less efficient than a system with belts and pulley wheels for the same drive ratio. Then again, a system with pulleys and wheels suffers from a shorter lifespan [11], but can quite easily be repaired for a minimal cost. For this particular design a system of pulleys and wheels was chosen due to the lower cost, higher efficiency and lower weight $[12,13]$.

\subsection{Overall Efficiency}

In order to obtain an overall high efficiency, one needs to consider the complete system, which includes the turbine, mechanical parts, like the ball bearings, pulley system as well as the electrical parts, like the generator, DC/DC converter and energy storage system. The DC/DC converter serves as a buffer to deal with the fluctuations of the wind speed, which result in changes to the output of the generator on one hand whereas there is the requirement for a constant supply towards the load or temporary energy storage.

When looking at overall efficiency, one first needs to look at the conversion from kinetic energy into mechanical energy, which has a maximum efficiency of $59.3 \%$. As mentioned previously, this efficiency $\left(\mathrm{C}_{\mathrm{P}}\right)$ is more likely to be in the range of $35 \%-45 \%$ depending on the type of turbine blades used [2]. With the rotational speed of turbine blades being rather low in the city environment, a drive system is used to increase the speed that reaches the generator. A drive system will have an efficiency of $80 \%-98 \%$ on average, depending on the drive ratio. Besides the drive system efficiency, one also needs to consider the efficiency of the DC generators, which is usually in the range of $80 \%-95 \%$ [14]. Therefore, the efficiency from mechanical energy into electrical energy $\left(C_{1}\right)$ is between 64 and $93 \%$.

To ensure a constant output voltage, a DC generator is used, which also has a certain efficiency. Depending on technical properties, and design parameters, the efficiency of this conversion $\left(\mathrm{C}_{2}\right)$ is in the range of $90 \%-96 \%$ [15]. Finally, the output power may be stored in batteries through a battery charger. The efficiency of chargers is generally very high, so this can be ignored, and batteries would have an efficiency of $85 \%$. Consequently, the total efficiency of the system during the conversion from kinetic wind energy into electrical energy $\left(\mathrm{C}_{\mathrm{p}} \times \mathrm{C}_{1} \mathrm{x}\right.$ $\mathrm{C}_{2}$ ) will be between $20 \%$ and $40 \%$.

\subsection{Electrical Design}

3.3.1. DC Generators In selecting an appropriate generator, it is highly important to select a generator with an output power that matches the mechanical output power of the turbines, because this leads to an optimal efficiency of operation. Therefore, several generators were selected based on the mechanical output power in combination with the expected rotational speeds. These values were calculated for a wide range of wind speeds after determining aerodynamic parameters such as: optimal tip speed ratio $(\lambda)$, power coefficient $\left(\mathrm{C}_{\mathrm{p}}\right)$, diameter of turbine and total predicted efficiency $(0.20-0.40)$. This resulted in the following required specifications for the DC generators: rated output voltage of $12 \mathrm{~V}$ or $24 \mathrm{~V}$, rated current at $0.02 \mathrm{~A}-10 \mathrm{~A}$, maximum output power of about $65 \mathrm{~W}$ for $18 \mathrm{~m} / \mathrm{s}$, a maximum width and length of the generators of $10 \mathrm{~cm}$ and $15 \mathrm{~cm}$ respectively to match with the turbine frame, a maximum rotational speed of about 4500rpm; and an efficiency in the range of $75 \%-95 \%$ [16]. Hence, following these requirements, three different generators were selected: (1) a $12 \mathrm{~V}-10 \mathrm{~W}$ - 4600rpm \& $0.077 \mathrm{Nm}$ generator; (2) a $24 \mathrm{~V}-19 \mathrm{~W}-3100 \mathrm{rpm} \&$ $0.058 \mathrm{Nm}$ generator and (3) a $12 \mathrm{~V}-30 \mathrm{~W}-2000 \mathrm{rpm}$ \& $0.14 \mathrm{Nm}$ DC generator.

3.3.2. DC/DC Converters The essential parameters to be taken into account when selecting a DC/DC converter are: input and output voltages, current and power, and the overall efficiency of the converter. While the input voltage of the DC generators frequently changes from $0 \mathrm{~V}$ to 12 OR $24 \mathrm{~V}$, depending on the generator, a boost converter will ensure a constant output at $24 \mathrm{~V}$. Therefore, a single boost converter with an input of $1.5 \mathrm{~V}-28 \mathrm{~V}$, and an output of $24 \mathrm{~V}$ output at max $3 \mathrm{~A}$, with an efficiency of $94 \%$ was selected.

3.3.3. Energy Storage The energy storage requirements in this project are generally small, therefore the most suitable solution will be to use either super-capacitors or batteries. Super capacitors are known to be good at storing energy that comes in and goes out in bursts, which is not quite the case in this application. Therefore, batteries are a much better solution since they provide for better longterm energy storage. Additional benefits to batteries lie in their high energy and power density, low maintenance costs, light weight and small size, portability and long shelf life [17, 18]. The most commonly found battery types are: lead-acid batteries, nickel cadmium batteries $(\mathrm{Ni}-\mathrm{Cd})$, nickel metal hydride batteries $(N i-M H)$, lithium ion 
batteries (Li-ion) and sodium sulphur batteries ( $\mathrm{Na}$ $S$ ). Each of these types has respective advantages and disadvantages and these are considered in relation to their use with a micro wind turbine. The different factors that are being considered for each battery type are: investment cost, energy and power density, shelf life, self-discharge, discharge time at rated power and efficiency. The comparison results of this study are summarized in Table 2 .

Table 2. Comparison of different battery types for energy storage

\begin{tabular}{|c|c|c|c|c|c|}
\hline \multicolumn{6}{|c|}{$\begin{array}{c}\text { The battery types are arranged in order of a gradually } \\
\text { increasing level for each evaluation factor }\end{array}$} \\
\hline \multicolumn{2}{|c|}{ Investment Cost } & \multirow{2}{*}{$\begin{array}{l}\text { Energy } \\
\text { density }\end{array}$} & \multirow{2}{*}{$\begin{array}{l}\text { Power } \\
\text { density }\end{array}$} & \multirow{2}{*}{$\begin{array}{l}\text { Life } \\
\text { Cycle }\end{array}$} & \multirow{2}{*}{$\begin{array}{c}\text { Self- } \\
\text { discharge }\end{array}$} \\
\hline$\$ / k W$ & $\begin{array}{c}\$ / \\
k W h\end{array}$ & & & & \\
\hline $\begin{array}{c}\text { Lead } \\
\text { acid }\end{array}$ & \multirow{2}{*}{$\begin{array}{c}\text { Lead } \\
\text { acid } \approx \\
\mathrm{NaS}\end{array}$} & $\begin{array}{l}\text { Lead } \\
\text { acid }\end{array}$ & $\begin{array}{c}\text { Lead } \\
\text { acid }\end{array}$ & $\begin{array}{c}\text { Lead } \\
\text { acid }\end{array}$ & Lead acid \\
\hline & & \multirow[b]{2}{*}{$\begin{aligned} & \mathrm{NiCd} \\
& \approx \mathrm{NiMH}\end{aligned}$} & \multirow[b]{2}{*}{$\begin{array}{l}\mathrm{NiCd} \approx \\
\mathrm{NaS}\end{array}$} & NiMH & \\
\hline $\begin{aligned} & \mathrm{NiCd} \\
\approx & \mathbf{N i M H}\end{aligned}$ & \multirow{2}{*}{$\begin{array}{l}\mathrm{NiCd} \\
\approx \mathbf{N i M} \\
\quad \mathbf{H}\end{array}$} & & & \multirow[t]{2}{*}{$\mathrm{NiCd}$} & $\begin{array}{l}\mathrm{NaS} \approx \mathrm{Li}- \\
\quad \text { ion }\end{array}$ \\
\hline $\mathrm{NaS}$ & & \multirow[b]{2}{*}{$\begin{array}{l}\mathrm{NaS} \approx \\
\text { Li-ion }\end{array}$} & NiMH & & $\mathrm{NiCd}$ \\
\hline Li-ion & Li-ion & & Li-ion & $\begin{array}{l}\mathrm{NaS} \approx \\
\mathrm{Li}-\mathrm{ion}\end{array}$ & NiMH \\
\hline \multicolumn{2}{|c|}{$\begin{array}{c}\text { Environmental } \\
\text { impact }\end{array}$} & \multicolumn{2}{|c|}{$\begin{array}{l}\text { Discharge time at } \\
\text { rated power }\end{array}$} & \multicolumn{2}{|c|}{ Efficiency } \\
\hline \multicolumn{2}{|c|}{$\begin{array}{l}\text { Lead acid - } \\
\text { Unfriendly } \\
\end{array}$} & \multicolumn{2}{|c|}{ Li-ion } & \multicolumn{2}{|c|}{ Lead acid } \\
\hline \multicolumn{2}{|c|}{ NiCd - Unfriendly } & \multicolumn{2}{|c|}{ Lead acid } & \multicolumn{2}{|c|}{$\mathrm{NiCd}$} \\
\hline \multicolumn{2}{|c|}{ NiMH - Friendly } & \multicolumn{2}{|c|}{$\mathrm{NiCd}$} & \multicolumn{2}{|c|}{ NiMH } \\
\hline \multicolumn{2}{|c|}{ Li-ion- Friendly } & \multicolumn{2}{|c|}{ NiMH } & \multicolumn{2}{|c|}{$\mathrm{NaS}$} \\
\hline \multicolumn{2}{|c|}{ NaS- Friendly } & \multicolumn{2}{|c|}{$\mathrm{NaS}$} & \multicolumn{2}{|c|}{ Li-ion } \\
\hline
\end{tabular}

As can be seen in Table 2, NiMH and $\mathrm{Na}-\mathrm{S}$ batteries have lower investment cost, and higher energy and power densities in comparison to other batteries. $\mathrm{NiMH}$ and $\mathrm{Na}-\mathrm{S}$ batteries are also highly efficient, and have a high discharge time at rated power. On top of that, their environmental impact is limited. When comparing $\mathrm{NiMH}$ and $\mathrm{Na}-\mathrm{S}$ type batteries, then NiMH batteries have lower life-cycle and higher self-discharge in comparison with $\mathrm{Na}-\mathrm{S}$ batteries. On the other hand, the investment cost $(\$ / \mathrm{kW}$ and $\$ / \mathrm{kWh})$ of NiMH batteries is lower than that of $\mathrm{Na}-\mathrm{S}$ batteries. Considering that $\mathrm{NiMH}$ batteries are not prone to memory effect, and that they have a high power density as well as being environmentally friendly [19] makes them perfectly suitable for this application.

In practice, four $12 \mathrm{~V}, 2 \mathrm{Ah}$ packs were used, of which two were put in series to provide $24 \mathrm{~V}$ storage and output. These sets were then combined in parallel to allow for higher output currents.

\section{Test results, analysis and discussion}

This section provides the measured data for the different combinations of turbines and generators, and looks more specifically at the following factors, namely: total efficiency, electric power output, selfstarting ability, power coefficient, and the simplicity of the mechanical structure. The measurement results of the micro turbines will be analysed and evaluated to select the most optimal turbine for building an array of micro VAWTs to improve the output electric power. The measured parameters are: current $\left(I_{D C}\right)$, voltage $\left(V_{D C}\right)$ generated from DC generators with respect to different loads and wind speeds; rotational speed $(n)$ and self-starting time $(t)$. From these measured parameters, the following parameters were calculated: mechanical output power $(P)$, electric output power of the DC generators $\left(P_{e}\right)$, torque produced from turbine blades $\left(T_{m}\right)$, power coefficient $\left(C_{p}\right)$; and total efficiency $\left(\eta_{\text {total }}\right)$ of the micro VAWT system.

\subsection{Influence of using different ball bearings}

Before looking at the results for the different turbines and generators, the different bearing types were tested. The three bearing types being tested include: 2-bolt circle bearings, taper-roller bearings, and ball bearings, which were tested with the different turbines. The results for these tests for the first turbine combined with a specific generator are shown in Table 3.

Table 3. Comparing the three different bearing types for Turbine 1 with a $12 \mathrm{~V} \& 10 \mathrm{~W}$ DC generator

\begin{tabular}{|c|c|c|c|c|}
\hline $\begin{array}{c}\text { Bearing } \\
\text { types }\end{array}$ & $\begin{array}{c}\text { Starting } \\
\text { wind } \\
\text { speed } \\
\text { (m/s) }\end{array}$ & $\begin{array}{c}\text { Self- } \\
\text { starting } \\
\text { time (s) }\end{array}$ & $\begin{array}{c}\text { Rotational } \\
\text { speed at } \\
\mathbf{8 m} / \mathbf{s} \\
\text { (rpm) }\end{array}$ & $\begin{array}{c}\text { Total } \\
\text { weight } \\
\text { (gram) }\end{array}$ \\
\hline $\begin{array}{c}\text { 2-bolt } \\
\text { bearings }\end{array}$ & 2.5 & 15 & 315 & 800 \\
\hline $\begin{array}{c}\text { Ball } \\
\text { bearings }\end{array}$ & 1.9 & 10 & 395 & 630 \\
\hline $\begin{array}{c}\text { Taper } \\
\text { roller } \\
\text { bearings }\end{array}$ & 1.5 & 10 & 400 & 628 \\
\hline
\end{tabular}

As can be noted from Table 3, there is a significant difference in weight for the different turbines when using the different types of bearings. Considering that the turbine itself did not change, this weight difference is purely due to the weight difference for the bearings, with $200 \mathrm{~g}, 30 \mathrm{~g}$, and $28 \mathrm{~g}$ for the 2-bolt circle bearings, ball bearings, and taper-roller bearings respectively. The lighter weight for the ball and taper roller bearings seems to have a positive effect on the turbine behaviour in comparison to the 2-bolt circle bearings. This results in a lower starting wind speed, better self-starting time and higher rotational speed at a wind-speed of 8 $\mathrm{m} / \mathrm{s}$. When comparing the ball bearings and taper roller bearings, the latter still has a slight advantage over the former, which translates in a better start speed and slightly higher rpm for an $8 \mathrm{~m} / \mathrm{s}$ windspeed. Therefore, based on the data in Table 3, one 
would conclude that taper-roller bearings are the most suitable type of bearings. However, there are a few other aspects to be taken into consideration, which are vibration level, force balance and energy efficiency. In terms of vibration level, the 2-bolt bearings perform best, closely followed by the ball bearings. The reason for their better performance lies in the sturdy constructions, whereas taper-roller bearings allow for easier decomposition and are therefore less solid to deal with any vertical forces in the system. Also in terms of force balance and energy efficiency do ball bearings form the most suitable solution for Turbine 1 .

For Turbines $2 \& 3$, a similar test of the three bearing types using the same generator was performed. In terms of measured data, again the taper-roller bearings are performing better than the other two types, with only a minor difference towards the ball bearings. On the other hand, at wind speed above $5 \mathrm{~m} / \mathrm{s}$, the vibration of the turbine blades when using taper-roller bearings is much higher than when using ball bearings. Hence, similar to the first Turbine, also for Turbines $2 \& 3$, ball bearings are the most suitable type of bearings.

\subsection{Turbine 1}

Figure 4 (a) \& (b) show the electrical power output and total efficiency when linking three different generators to Turbine 1. From the graphs, it can be seen that the total efficiency of the $24 \mathrm{~V} \&$ 19W DC generator increases strongly between a wind speed of $3 \mathrm{~m} / \mathrm{s}$ to $7 \mathrm{~m} / \mathrm{s}$, and reaches its highest percentage of $32.8 \%$ in comparison to the other generators from wind speeds above $7 \mathrm{~m} / \mathrm{s}$. Although the electric power produced by the $12 \mathrm{~V} \& 30 \mathrm{~W}$ generator is higher than that of the $24 \mathrm{~V} \& 19 \mathrm{~W}$ generator, the cut-in wind speed when using this $12 \mathrm{~V}$ \& $30 \mathrm{~W}$ generator is much higher (at $5 \mathrm{~m} / \mathrm{s}$ in comparison to $3 \mathrm{~m} / \mathrm{s}$ for the turbine using the $12 \mathrm{~V} \&$ $19 \mathrm{~W}$ generator). The latter is probably due to the larger electrical power output specification for this generator, which would mean that more kinetic energy is required to start rotating the generator. As a result, using the $24 \mathrm{~V} \& 19 \mathrm{~W}$ DC generator is the most optimal solution in combination with Turbine 1 .

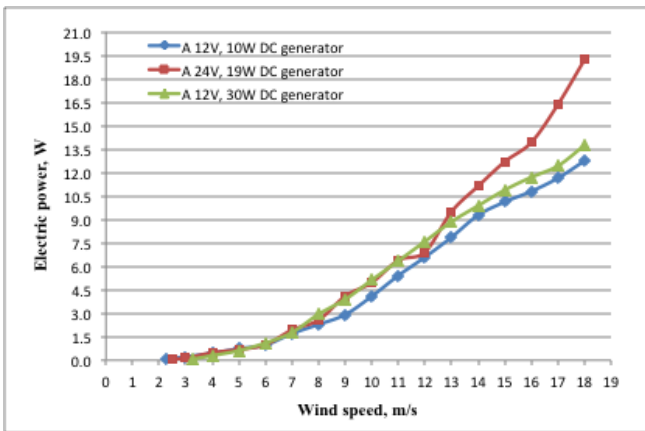

(a) Electric power output for three different generators

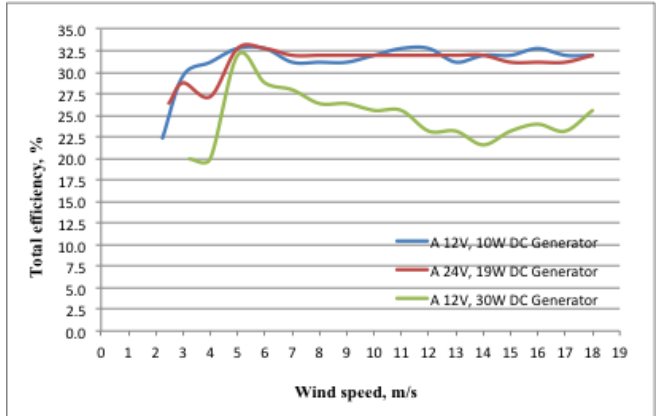

(b) Total efficiency with regard to different generators

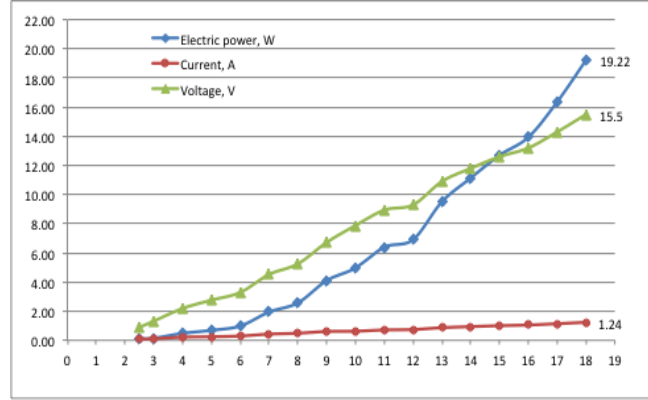

(c) Variations of electric power, voltage \& current for Turbine 1 using the $24 \mathrm{~V} \& 19 \mathrm{~W}$ DC generator

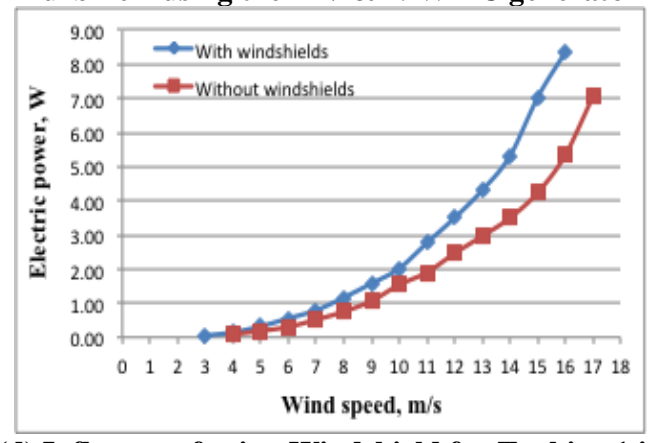

(d) Influence of using Windshield for Turbine 1 in combination with the $24 \mathrm{~V} \& 19 \mathrm{~W}$ DC generator

Figure 4. Measurement data for Turbine 1

The variations of electric power, output voltage and current of Turbine 1 using the $24 \mathrm{~V} \& 19 \mathrm{~W}$ DC generator are shown in Figure 4 (c). The changes of current are insignificant when the output of the $24 \mathrm{~V}$ $\& 19 \mathrm{~W}$ generator is connected to a load in response to different wind speeds (from $0.07 \mathrm{~A}$ at $2.5 \mathrm{~m} / \mathrm{s}$ to $1.24 \mathrm{~A}$ at $18 \mathrm{~m} / \mathrm{s}$ ). The output voltage strongly rises in correspondence to the change in wind speeds (from $0.89 \mathrm{~V}$ at $2.5 \mathrm{~m} / \mathrm{s}$ to $15.5 \mathrm{~V}$ at $18 \mathrm{~m} / \mathrm{s}$ ). Additionally, electric power generated from Turbine 1 at $2.5 \mathrm{~m} / \mathrm{s}$ is only $0.06 \mathrm{~W}$, whereas for an average wind speed of $8 \mathrm{~m} / \mathrm{s}$, it is $2.57 \mathrm{~W}$. For a safe wind speed of Turbine 1 at $18 \mathrm{~m} / \mathrm{s}$, the generator generates a power of $19.22 \mathrm{~W}$.

Figure 4 (d) also indicates a clear advantage of using the windshields in combination with the SType blades of Turbine 1 . The advantage becomes more prominent with increasing wind speeds. 


\subsection{Turbine 2}

Similar to Turbine 1, the results for using the different generators in combination with Turbine 2 are shown in Figure 5 (a) \& (b). A similar trend can be seen in relation to total efficiency, where the $24 \mathrm{~V}$ \& 19W generator now seems to compete more closely with the $12 \mathrm{~V} \& 10 \mathrm{~W}$ generator. When considering the electrical power, it is again the generators with the higher power output specification that provide a higher output. In overall, one can again see that the $24 \mathrm{~V} \& 19 \mathrm{~W}$ generator forms the better solution when combined with this turbine. The influence of combining the S-type blades with the $\mathrm{H}$ type blades is shown in Figure 5 (c).

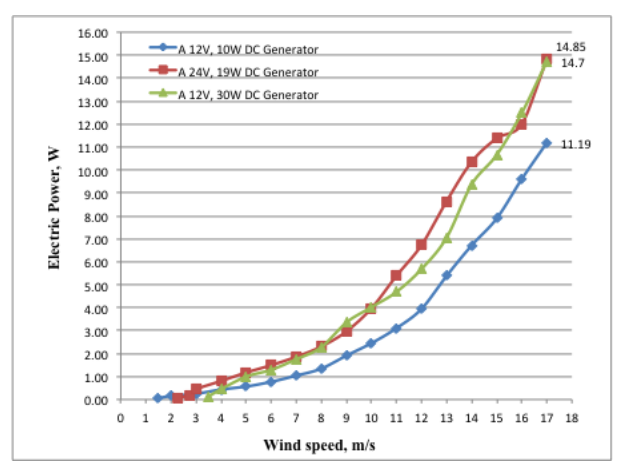

(a) Electric power output with respect to wind speeds for three different DC generators in Turbine 2

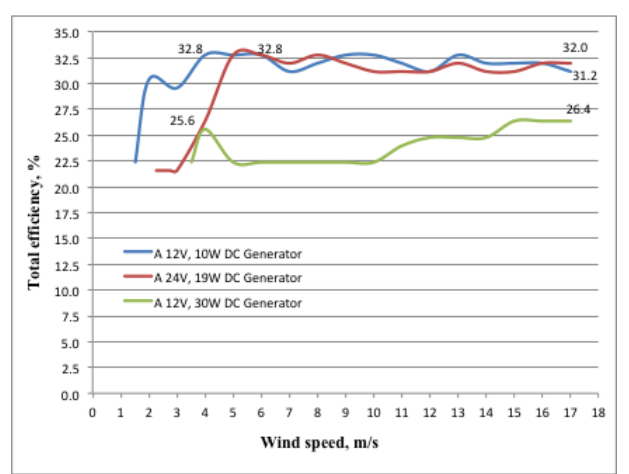

(b) Total efficiency of Turbine 2 with regard to three different DC generators

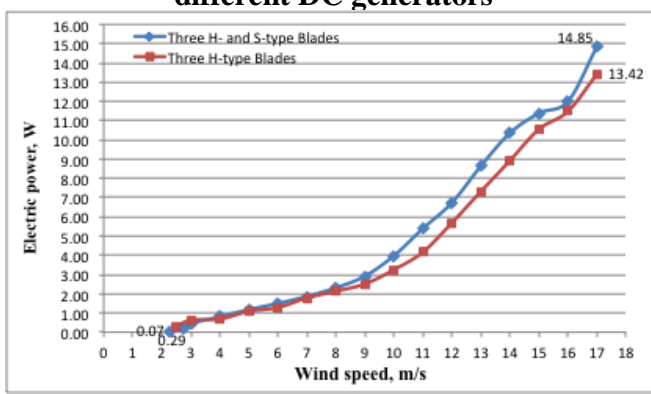

(c) Influence of using H-type blades with Turbine 2 in combination with the $24 \mathrm{~V} \& 19 \mathrm{~W}$ DC generator

Figure 5. Results for Turbine 2

\subsection{Turbine 3}

In contrast to the results for the first two turbines, the Darrieus-type turbine provides slightly different results, as can be seen in Figure 6. Using this turbine with the $24 \mathrm{~V} \& 19 \mathrm{~W}$ DC generator is not feasible due to the high starting and cut-in wind speeds as well as the small voltage and electric power as summarized in Table 4 . This table clearly shows that the starting and cut-in wind speeds and self-starting time of the $24 \mathrm{~V} \& 19 \mathrm{~W}$ and $12 \mathrm{~V} \& 30 \mathrm{~W}$ DC generators are very high, e.g. at $4.5 \mathrm{~m} / \mathrm{s}$ and $5.5 \mathrm{~m} / \mathrm{s}$ for starting and cut-in wind speeds, and $38 \mathrm{~s}$ and $45 \mathrm{~s}$ for the self-starting time for the $24 \mathrm{~V} \& 19 \mathrm{~W}$ and $12 \mathrm{~V} \& 30 \mathrm{~W}$ generators respectively. The $12 \mathrm{~V} \&$ $10 \mathrm{~W}$ DC generator has $2.75 \mathrm{~m} / \mathrm{s}$ and $3.5 \mathrm{~m} / \mathrm{s}$ as starting and cut-in wind speeds, and 30 s for the selfstarting time. Thus, the $12 \mathrm{~V} \& 30 \mathrm{~W}$ generator is certainly not suitable in combination with this turbine from the aspect of total efficiency. This is largely due to the fact that this turbine does not have a large mechanical power, therefore making it impossible to extract much energy from the wind. Consequently, a generator with a lower specification turns out more beneficial for this turbine.

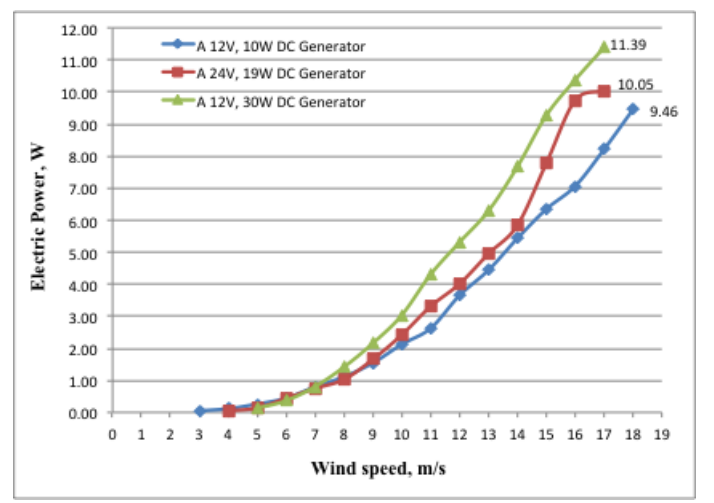

(a) Electric power output the different DC generators

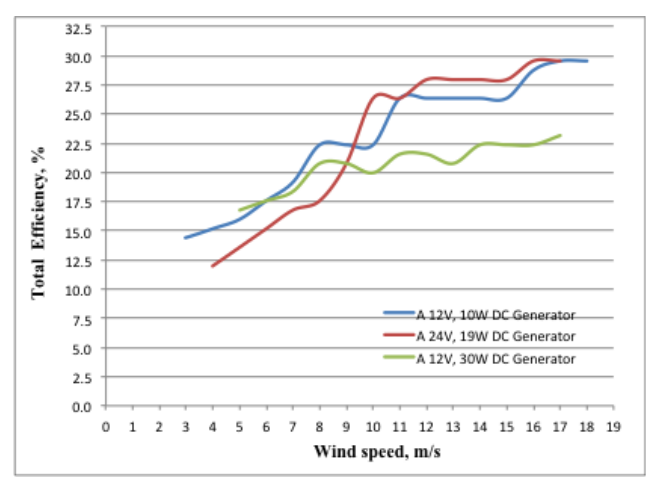

(b) Total efficiency for the different generators Figure 6. Results for Turbine 3 
Table 4. Measured parameters of three different generators for Turbine 3 .

\begin{tabular}{|c|c|c|c|}
\hline \multirow{2}{*}{$\begin{array}{l}\text { Measured } \\
\text { parameters }\end{array}$} & \multicolumn{3}{|c|}{ DC Generators } \\
\hline & $\begin{array}{l}12 \mathrm{~V} \& \\
10 \mathrm{~W}\end{array}$ & $\begin{array}{c}24 V \& \\
19 W\end{array}$ & $\begin{array}{c}12 \mathrm{~V} \& \\
30 \mathrm{~W}\end{array}$ \\
\hline Starting Wind Speed & $2.75 \mathrm{~m} / \mathrm{s}$ & $3.5 \mathrm{~m} / \mathrm{s}$ & $4.5 \mathrm{~m} / \mathrm{s}$ \\
\hline Cut-in Wind Speed & $3.5 \mathrm{~m} / \mathrm{s}$ & $4.5 \mathrm{~m} / \mathrm{s}$ & $5.5 \mathrm{~m} / \mathrm{s}$ \\
\hline Safe Wind Speed & $17 \mathrm{~m} / \mathrm{s}$ & $17 \mathrm{~m} / \mathrm{s}$ & $17 \mathrm{~m} / \mathrm{s}$ \\
\hline Self-Starting Time & $30 s$ & $38 s$ & $45 s$ \\
\hline
\end{tabular}

\subsection{Comparing the different turbines}

Considering the results presented for the individual turbines, it is no surprise that the power produced by Turbine 3 is lower than that produced by Turbines $1 \& 2$, as shown in Figure 7 (a). While Turbine 2 produces a higher electrical power for wind speeds below $8 \mathrm{~m} / \mathrm{s}$, from wind speeds of $8 \mathrm{~m} / \mathrm{s}$ and above Turbine 1 generates more electrical power. The benefit towards Turbine 2 for lower wind speeds is mainly related to the lower turbine weight, which is only 592g for Turbine 2 versus $630 \mathrm{~g}$ for Turbine 1. Considering that these turbines are designed for use in a city environment with low wind speeds, Turbine 2 is the better solution generating electrical power in this setting.

A second factor of comparison is the total efficiency as indicated in Figure 7 (b) for each of the turbines. The graph clearly shows that Turbine 3 has the lowest total efficiency, which is again no surprise. When comparing Turbines 1 and 2, then the differences are only marginal, since for a wind speed of $2 \mathrm{~m} / \mathrm{s}$ to $5 \mathrm{~m} / \mathrm{s}$, the total efficiency increases from $26.4 \%$ to $32.8 \%$ after which it remains stable within the range of $31.2 \%$ to $32 \%$. Considering this similarity in values, further investigation is required to determine the most efficient turbine.

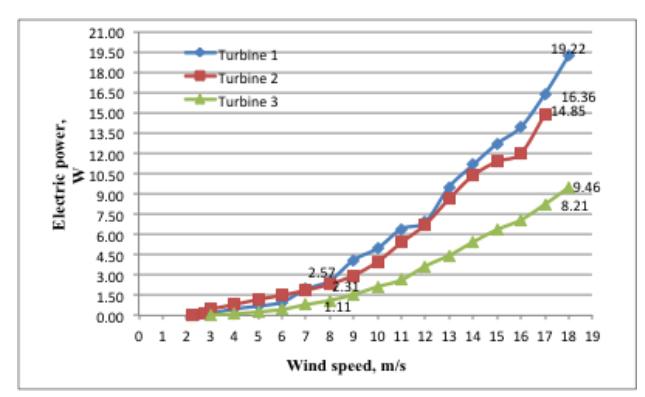

(a) Electric power output

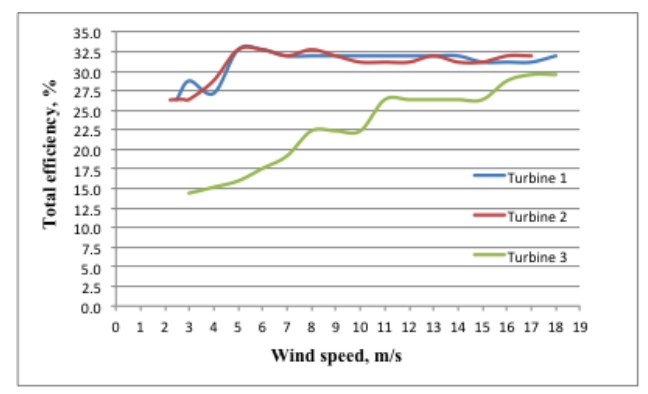

(b) Total efficiency

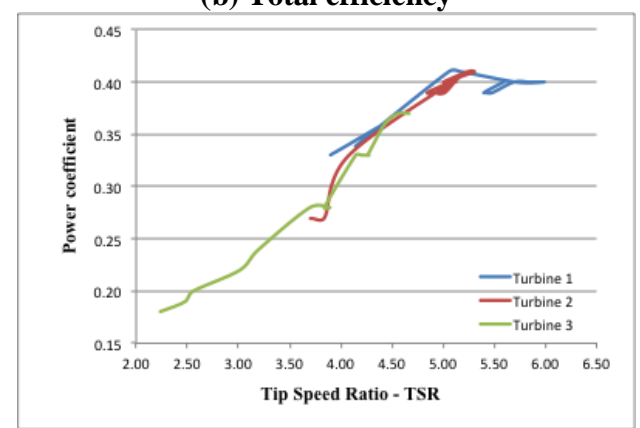

(c) Power coefficient

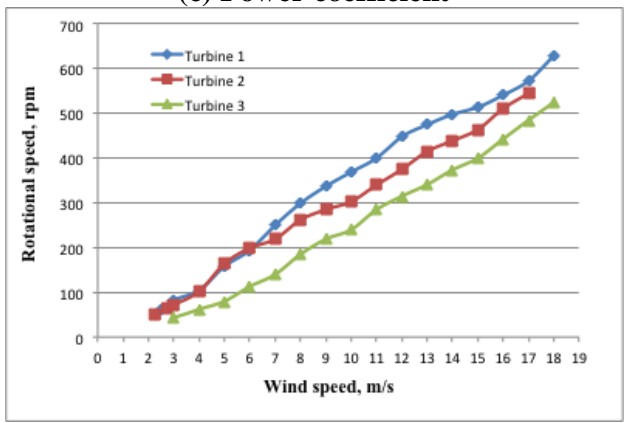

(d) Rotational Speed

Figure 7. Comparison of the different turbines

Table 5 shows the start and cut-in wind speeds as well as the self-starting time with respect to the three turbines. Again, Turbines 1 and 2 are very close to one another, especially when it comes to starting wind speed at $2.5 \mathrm{~m} / \mathrm{s}$ and $2.25 \mathrm{~m} / \mathrm{s}$ respectively, the self-starting time at $10 \mathrm{~s}$, and the rotational speed of turbine blades without being connected to a DC generator at $395 \mathrm{rpm}$ and $400 \mathrm{rpm}$ respectively for a wind-speed of $8 \mathrm{~m} / \mathrm{s}$. Although Turbine 3 has a significant weight advantage, its self-starting and rotational speeds results are worse than the other turbines (see Figure 7 (d)).

Table 5. Self-starting ability for three turbines

\begin{tabular}{|c|c|c|c|}
\hline DATA & $\begin{array}{c}\text { Turbine } \\
\mathbf{1}\end{array}$ & $\begin{array}{c}\text { Turbine } \\
\mathbf{2}\end{array}$ & $\begin{array}{c}\text { Turbine } \\
\mathbf{3}\end{array}$ \\
\hline $\begin{array}{c}\text { Starting Wind } \\
\text { Speed }\end{array}$ & $2.5 \mathrm{~m} / \mathrm{s}$ & $2.25 \mathrm{~m} / \mathrm{s}$ & $2.75 \mathrm{~m} / \mathrm{s}$ \\
\hline Self-starting Time & $10 \mathrm{~s}$ & $10 \mathrm{~s}$ & $20 \mathrm{~s}$ \\
\hline $\begin{array}{c}\text { Rotational Speed at } \\
8 \mathrm{~m} / \mathrm{s}, \text { not connect } \\
\text { to a DC generator }\end{array}$ & $395 \mathrm{rpm}$ & $400 \mathrm{rpm}$ & $305 \mathrm{rpm}$ \\
\hline Weight & $630 \mathrm{~g}$ & $592 \mathrm{~g}$ & $482 \mathrm{~g}$ \\
\hline
\end{tabular}

The turbines should also be compared in relation to their power coefficient, for which the results are shown in Figure 7 (c) and their rotational speed (see Figure 7 (d)). Once again Turbine 3 is not performing particularly well in comparison with the other turbines. When comparing Turbine 1 and 2, then it seems that Turbine 1 has a slightly better power coefficient in comparison to Turbine 2 . The difference is however so small, that once again both 
turbines can be considered as suitable for use in low wind conditions.

With regards to mechanical construction, Turbine 3 is the most complicated turbine to construct, whereas Turbines $1 \& 2$ are simpler. When comparing the latter two turbines, then the construction of Turbine 2 is slightly more complicated due to the shape of the three H-type blades.

\section{Table 6. Comparison of all factors for the} different turbines

\begin{tabular}{|l|c|c|c|}
\hline \multicolumn{1}{|c|}{ Evaluation factors } & $\begin{array}{c}\text { Turbine } \\
\mathbf{1}\end{array}$ & $\begin{array}{c}\text { Turbine } \\
\mathbf{2}\end{array}$ & $\begin{array}{c}\text { Turbine } \\
\mathbf{3}\end{array}$ \\
\hline $\begin{array}{l}\text { 1. Electric power } \\
\text { produced by each VAWT } \\
\text { in low wind conditions }\end{array}$ & High & Highest & Low \\
\hline $\mathbf{2 .}$ Total Efficiency & High & High & Low \\
\hline $\begin{array}{l}\text { 3. } \text { Cut-in wind speed and } \\
\text { self-starting time } \\
\text { - Starting wind speed and } \\
\text { weight }\end{array}$ & Low & Low & High \\
\hline $\begin{array}{l}\text { 4. Power coefficient and } \\
\text { rotational speed }\end{array}$ & High & High & Low \\
\hline $\begin{array}{l}\text { 5. Mechanical } \\
\text { construction complexity }\end{array}$ & Simplest & Simple & Complex \\
\hline
\end{tabular}

The different parameters used for comparing the three designed turbines are all summarized in Table 6. When considering all parameters, then one can conclude that Turbine 2 is the most efficient turbine to use in a build-up area. The main advantages of this turbine lie in the fact that it produces the highest electric power at low wind speeds and it also has the lowest starting wind speed. The total efficiency, cutin wind speed, self-starting time, power coefficient and the rotational speed of turbine 2 are then again similar to those of Turbine 1. In spite of the mechanical structure, modern machines should not have any problems to construct Turbine 2 easily and cheaply.

\section{Conclusion}

This paper considered several turbine designs for micro wind turbines to be used in built up areas with low wind speeds that can also quickly change direction. The turbines had a maximum diameter of $30 \mathrm{~cm}$ and are designed to power low voltage DC appliances. Vertical Axis Wind Turbines were selected because they can easily deal with the changes in wind direction that will be experienced in the area they are designed for. A variety of different prototypes that combine different type of blades, including Savonius, H-type and Darrieus were tested. The Savonius and H-type were combined with windshields and S-type blades respectively to enhance their performance. The paper also considered the overall system performance and tested different ball bearings and generators with each of the turbines.

Among the tested prototypes, the 3-blade S-type combined with H-type blades is considered the most optimal design to be used in build-up environments. The overall efficiency of this turbine is $31.2 \%$, with a power coefficient of 0.42 , which is above average considering that the total efficiency is generally within the range of 20 to $40 \%$. Additionally, the turbine has a low starting and cut-in wind speed at $2.25 \mathrm{~m} / \mathrm{s}$ and $2.75 \mathrm{~m} / \mathrm{s}$ respectively and a low starting time of $10 \mathrm{~s}$. This turbine, when combined with a $24 \mathrm{~V}$ \& 19W DC generator, can provide energy via a DC/DC converter to a DC storage system that can then provide an output at $24 \mathrm{~V}$.

The electrical power output of Turbine 2 connected to a $24 \mathrm{~V}, 19 \mathrm{~W} \& 0.058 \mathrm{Nm}$ DC generator is about $12 \mathrm{~W}$ at an average wind speed of $8 \mathrm{~m} / \mathrm{s}$. The maximum charge time of four $12 \mathrm{~V} \& 2 \mathrm{Ah}$ therefore becomes 25 hours. Hence, depending on the power demands, a multitude of turbines might be required. For example, in order to supply electricity to some DC devices, such as: a radio (10W), a CD player (30W), LED-lights, two electric fans (50W) or two laptops (120W), it may therefore be essential to build an array of 10 micro VAWTs which would provide a total power of $120 \mathrm{~W}$, leading to an annual production of $1314 \mathrm{kWh} /$ year, and this at an estimative capital cost of nearly $£ 1 \mathrm{k}$.

Although the overall output of the presented micro turbines is small, the paper shows that these turbines might provide an alternative source of energy that can be used in city environments and therefore further improvements of turbine design will be researched.

\section{Acknowledgements}

The authors would like to thank the Vietnamese government for providing the finances to allow $\mathrm{Mr}$. Duong Bui to study at the University of Greenwich. Furthermore, the authors would like to thank everyone who helped making this project successful.

\section{References}

[1] A.D. Sahin, "Progress and recent trends in wind energy", in Review Article Progress in Energy and Combustion Science, vol. 30, issue 5, 2004, pp. 501-543.

[2] W. Shepherd and L. Zhang, Electric Generation Using Wind Power, London, World Scientific, 2011.

[3] L. Ledo, P.B. Kosasih, et al, "Roof mounting site analysis for micro wind turbines", in Renewable Energy, vol. 36, issue 5, 2011, pp. 1379-1391.

[4] S. Mertens, "The energy yield of roof-mounted wind turbines," in Renewable Energy and Wind Power, vol. 27, issue 6, 2003, pp. 507-525. 
[5] N. Mithraratne, "Roof-top wind turbines for microgeneration in urban houses in New Zealand," in Energy and Buildings, vol. 41, issue 10, 2009, pp. 1013-1018.

[6] D. Weisser, "A wind energy analysis of Grenda: an estimation using the Weibull density function", in Renewable Energy, vol. 28, 2003, pp.1803-1815.

[7] M. Jureczko, M. Pawlak, and A. Myk, "Optimisation of wind turbine blades", in Journal of Materials Processing Technology, vol. 167, issues 2-3, 2005, pp. 463-471.

[8] M. Islam, S.K. Ting, and A. Fartaj, "Aerodynamic models for Darrieus-type straight-bladed vertical axis wind turbines", in Renewable and Sustainable Energy Reviews, Vol. 12, Issue 4, 2008, pp. 1087-1109.

[9] Quiet Revolution Ltd, Vertical Axis Wind Turbine Radar Impact Assessment. [Accessed on: 13/06/2012]. Available from: www.quietrevolution.com/qr5-turbine.htm

[10] N. Tandon and A. Choudhury, "A review of vibration and acoustic measurement methods for the detection of defects in rolling element bearings", in Tribology International, vol. 32, issue 8, 1999, pp. 469-480.

[11] C. Gregor and B. Miha, "Dynamics of a belt-drive system using a linear complementarity problem for the belt-pulley contact description", in Journal of Sound and Vibration, vol. 319, issues 3-5, 2009, pp. 1019-1035.

[12] S. Nilabh and H. Imtiaz, "A review on belt and chain continuously variable transmissions (CVT): Dynamics and Control", in Mechanism and Machine Theory, vol. 44, issue 1, 2009, pp. 19-41.

[13] P. Ettore, et al, "Efficiency evaluation of gearboxes for parallel hybrid vehicles: Theory and Applications" in Mechanism and Machine Theory, vol. 49, 2012, pp. 157176.

[14] J.E. Bruemmer, F.R. Williams, and G.V. Schmitz, "Efficient design in a DC to DC converter unit," in Energy Conversion Engineering Conference, 37th Intersociety, USA, 2002, pp. 56-60.

[15] K. Pill-Soo and K. Yong, "A future cost estimation on small DC motor using learning curve analysis", in Proceedings of Power Electronics and Drive Systems, vol. 2, 2001, pp. 565 570, 10.1109/PEDS.2001.975380.

[16] "Efficiency in small permanent magnet DC generators", [Accessed on: 13/06/2012], Available from: www.windstreampower.com/documents.

[17] K.C. Divya, "Battery energy storage technology for power systems - An overview," in Electric Power Systems Research, vol. 79, issue 4, 2009, pp. 511-520.

[18] C.N. Nirmal-Kumar and N., Garimella, "Battery energy storage systems: Assessment for small-scale renewable energy integration", in Energy and Buildings, vol. 42 , issue 11,2010 , pp. 2124-2130.
[19] J. Dunbar, "High performance nickel metal hydride batteries", WESCON/94Idea/Microelectronics Conference Record, Anaheim, CA, USA, 1994. 